\title{
EDUCAÇÃO EM SAÚDE PARA ADOLESCENTES: CONSTRUÇÃO DE UMA TECNOLOGIA DIDÁTICA PARA PROFESSORES
} http://doi.org/10.48195/sepe2021-070

\section{Pabline Pivetta de Oliveira'; Gicelle Moraes Martelli2; Dielli Arend Teixeira ${ }^{3}$; Graziele Alves Flores ${ }^{4}$; Josiane Lieberknecht Wathier Abaid 5; Luana Fietz da Silva Raznievski ${ }^{6}$; Raquel de Oliveira Costa Lunkes ${ }^{7}$ Regina Gema Santini Costenaro ${ }^{8}$}

\section{RESUMO}

Objetiva-se construir uma tecnologia didática do tipo cartilha informativa com orientações de cuidado e autocuidado, para prevenção da gravidez e Infecção Sexualmente Transmissível (IST) na adolescência. Estudo do tipo pesquisa qualitativa, com abordagem a uma tecnologia didática. Desenvolvida por acadêmicos e docentes do curso de enfermagem da Universidade Franciscana, como produto do projeto "prevenção da gravidez e infecções sexualmente transmissíveis na adolescência-Tecnologia didática para professores". Público-alvo foram profissionais da educação e adolescentes da rede pública de educação, no periodo de 2020 a 2021. A cartilha contemplou uma breve introdução, perguntas frequentes e elencadas as seguintes IST's: Sífilis, Aids, Candidíase, Clamídia, Herpes Genital, Hepatite B, Tricomoníase, Herpes, Citomegalovírus, Vírus do Papiloma Humano (HPV), Gonorreia. Em cada IST discutiu-se as características da infecção, prevenção, sinais e sintomas, transmissão, diagnóstico e tratamento. Por fim, a cartilha foi um material relevante para as escolas. Pois, aborda a prevenção da gravidez e IST's na adolescência, características das IST's e como agir frente a contaminação.

\footnotetext{
${ }^{1}$ Acadêmica de Enfermagem da Universidade Franciscana (UFN). Bolsista PROBIC. pablinepivetta@gmail.com

${ }^{2}$ Acadêmica de Enfermagem da Universidade Franciscana (UFN). Bolsista PROBIC. gicelle.martelli@ufn.edu.br

${ }^{3}$ Acadêmica de Enfermagem da Universidade Franciscana (UFN). Bolsista Voluntária PROBIC. dielli.arend@ufn.edu.br

${ }^{4}$ Acadêmica de Enfermagem da Universidade Franciscana (UFN). Bolsista FAPERGS. graziele.flores@ufn.edu.br

${ }_{5}^{5}$ Psicóloga. Doutora em Psicologia. Professora do curso de psicologia da Universidade Franciscana (UFN). josianelieb@ufn.edu.br

${ }_{6}^{6}$ Pedagoga. Coordenadora do PSE- Secretaria Municipal de Educação de Santa Maria-SMED.

Luana.raz@edu.santamaria.rs.gov.br

${ }^{7}$ Mestranda em Saúde Materno Infantil da Universidade Franciscana (UFN). raquellunkes@ufn.edu.br

8 Enfermeira. Doutora em Enfermagem. Docente do curso de Enfermagem da Universidade

Franciscana (UFN). Reginacostenaro@gmail.com
} 
Palavras-chave: Adolescência; Educação em Saúde; Enfermagem; Gravidez na Adolescência; IST.

\section{Eixo Temático: Atenção Integral e Promoção à Saúde (AIPS)}

\section{INTRODUÇÃO}

O período da adolescência é caracterizado por diversas mudanças biopsicossociais no organismo do adolescente. A mudança de comportamento sexual é um marco do desenvolvimento, e o início precoce das relações sexuais possibilitam a ocorrência da gravidez na adolescência e/ou torna vulneráveis as Infecções Sexualmente Transmissíveis (IST's). Isto pode estar relacionado a falta de informações e ao uso incorreto dos métodos contraceptivos, o que expõe os adolescentes ao risco (COSTENARO et al., 2020; RODRIGUES, 2017).

A gestação na adolescência pode gerar muitas limitações na trajetória de vida das adolescentes, visto que, à maternidade precoce, sem o preparo físico do corpo, carência de saúde mental e dificuldades econômicas, viabiliza problemas psicológicos, afetivos e sociais (ROSANELI; COSTA; SUTILE, 2020). Bem como, as IST's que geram consequências de curta ou longa duração, alterações fisiológicas e por vezes patológicas significativas, além de possibilitar a transmissão para outros adolescentes pela falta de conhecimento dos seus sinais e sintomas (ALBUQUERQUE, 2019).

Nesse contexto, a educação em saúde voltada a promoção do autocuidado e da prática do sexo seguro, como prevenção da gravidez na adolescência e IST's devem ser enfatizados aos adolescentes por meio de metodologias didáticas, como uma das responsabilidades quanto as práticas e atitudes no exercício da sexualidade com saúde (VIEIRA et al., 2021). Dado que, o Ministério da Educação, por meio dos Parâmetros Curriculares Nacionais (PCN) integra a orientação sexual entre os temas transversais nas diversas áreas do conhecimento, com objetivo de incluir práticas educativas relacionadas às questões da orientação sexual (FURLANETTO; LAUERMANNII; COSTA; MARIN, 2018).

O cenário escolar, deve ser considerado de suma importância para o 
desenvolvimento de atividades educativas em saúde, abordando questões que possam evitar as IST's e a gravidez precoce. Desta forma, os profissionais de educação e de saúde, devem ter conhecimento a respeito da temática afim de realizar um trabalho direcionado, sistematizado e contínuo, pois a adolescência, envolve um período complexo do crescimento e desenvolvimento humano (ALBUQUERQUE, 2019).

Diante disso, o uso de metodologias didáticas como cartilhas informativas são bem aceitas como ferramentas de educação para a saúde. Holanda (2018), ressalta que a utilização de materiais informativos como as cartilhas são positivos para ampliar o conhecimento em saúde relacionado a medidas de autocuidado, prevenção, tratamento e agravos, tanto para os profissionais quanto para adolescentes. Ademais, esses materiais voltados para a educação promovem impacto positivo na saúde dos adolescentes, pois trazem respostas as suas dúvidas.

Stankowski et al., (2021) enfatiza a importância dos profissionais da saúde como comunicadores, cuidadores e detentores da promoção de saúde dos adolescentes, seja por meio do PSE nas escolas ou no acolhimento pela atenção primária de saúde. Sabe-se que a gravidez e ISTs na adolescência são vivenciados por muitos adolescentes, por conta de vários aspectos, quais sejam: falta de informações sobre a temática, dificuldade de acesso aos serviços de saúde, baixa classe econômica, baixa escolaridade, carência ou ausência de comunicação com pais, familiares próximos ou pessoas que possam confiar.

Por fim, os profissionais da saúde necessitam estar articulados com os professores, observando as fragilidades e transmitindo novos conhecimentos. A partir de capacitações e materiais didáticos, assim atualizando os profissionais da educação quanto aos temas que se observa maior vulnerabilidade e/ou falta de domínio, além de, conferir maior qualidade nas orientações e ensino aprendizagem os adolescentes. Este trabalho tem por objetivo construir uma tecnologia didática do tipo cartilha informativa com orientações de cuidado e autocuidado, a fim de prevenir a gravidez e as ISTs na adolescência. 


\section{METODOLOGIA}

Pesquisa tecnológica educativa e informativa, em que foi construída uma cartilha, como ferramenta didática de educação para a saúde. Os materiais educativos e informativos impressos, tal como, a cartilha são considerados de extrema relevância no processo de educação e desenvolvimento, dado que, viabiliza o acesso a determinados assuntos de forma fácil, didática e inovadora (ALBUQUERQUE, 2016).

A cartilha informativa foi desenvolvida por acadêmicos e docentes do curso de enfermagem da Universidade Franciscana, como metodologia didática realizada como produto do projeto "prevenção da gravidez e infecções sexualmente transmissíveis na adolescência-Tecnologia didática para professores", sob número do Parecer: 3.778.921.

Esta cartilha é destinada aos profissionais de saúde e da educação, bem como aos adolescentes. Os temas contemplados na cartilha, relacionam-se a prevenção de gravidez e IST's na adolescência, sinais e sintomas, tratamento, consequências, modo de transmissão. O direcionamento da escrita origina-se da experiência da orientadora a qual vem abordando está temática, na comunidade escolar, a mais de 20 anos, sempre almejando integrar ensino-serviço-comunidade.

A cartilha possui 50 páginas, ilustradas e com escrita acessível, acompanhada de exercícios para serem realizados em sala de aula com os adolescentes. O período de desenvolvimento da cartilha informativa foi de agosto de 2020 até agosto de 2021.

\section{RESULTADOS E DISCUSSÕES}

A cartilha contemplou uma breve introdução do que é IST's e perguntas frequentes, após foi elencada as seguintes IST's: Sífilis, Aids, Candidíase, Clamídia, Herpes Genital, Hepatite B, Tricomoníase, Herpes, Citomegalovírus, Vírus do Papiloma Humano (HPV), Gonorreia. Em cada uma das IST's foi discutido sobre as características da infecção, como prevenir, sinais e sintomas, modo de transmissão, diagnostico e se há tratamento ou não. 
O material informativo foi elaborado de forma didática e de fácil entendimento, contendo imagens ilustrativas que facilitam o entendimento tanto dos professores quanto dos alunos para posteriores revisitações quando surgir dúvidas. Albuquerque (2016) destaca que o uso de ilustrações é imprescindível na comunicação em saúde, uma vez que, auxilia na compreensão do texto, assimilação e simplifica termos complexos, ressaltando aspectos importantes.

Rodrigues (2017) mostra que cada vez mais é necessário trabalhar com adolescentes temas como sexualidade, gravidez e IST's na adolescência. Visto que, a sexualidade faz parte da vida, é singular e compreende aspectos biopsicossociais, o que demanda de uma abordagem voltada para a educação sexual, visando desenvolver ferramentas que reduzam os índices de gravidez e IST's na população adolescente.

Para que os adolescentes possam prevenir o surgimento de doenças, é necessário que saibam reconhecer seus sinais e sintomas para identificar a patologia e introduzir medidas que possam limitar seus efeitos.

Nesse sentido, Albuquerque (2019) ressalta a utilização da cartilha como método de conscientização sobre as inúmeras consequências das IST's na vida dos adolescentes. Bem como, quais forma de prevenção. Como por exemplo, o uso correto do preservativo nas relações sexuais, este que pode prevenir a sífilis, HIV, hepatite $B$, entre outras.

Rizzon et al., (2021) enfatiza que embora os adolescentes manifestem conhecimento em relação a educação sexual, demonstram uma falha no real entendimento, dado que há um aumento significativo da não utilização de preservativo da primeira para a última relação sexual. Isso ocorre, geralmente, pela confiança no parceiro ou pelo uso de metodos conteceptivos pela adolescente. Entretanto, os adolescentes nao consideram a possibilidade de transmitir alguma IST. Desse modo, observa-se a necessidade de discutir esse tema, antes da idade de iniciação sexual, nas escolas, na tentativa de levar maior conhecimento para a população de adolescentes.

No entanto, para que seja abordado esses temas no ambiente escolar é preciso que os profissionais da educação tenham embasamento teórico e 
metodologias ativas para envolver os adolescentes, o que vai ao encontro da cartilha desenvolvida. Esta que leva conhecimento e orientações para os professores se empoderar do material e posteriormente abordar com os alunos.

Discutir educação sexual, afetividade e sexualidade também deveriam ser papel dos responsáveis e familiares dos adolescentes. Todavia, Gonçalves; Faleiro; Malafaia (2013) observam que a entraves no ambiente familiar para discutir essa temática, devido valor negativo atribuído ao sexo, pensam que os filhos não são seres sexuados e que essa abordagem antecipará a prática do ato sexual. Assim fica evidente a dificuldade de os responsáveis compreender que educação sexual vai além do ato sexual.

Nessa perspectiva, a responsabilidade de abordar esses assuntos sobre cai aos profissionais da educação, estes que precisam entender a importância de desenvolver discussões partindo do que os adolescentes sabem, das dúvidas e vulnerabilidades. Possibilitar a autonomia do adolescente para construir ativamente seu conhecimento a partir das discussões. Importante destacar que sejam utilizadas dinâmicas e linguagem de fácil compreensão nas práticas educacionais (ALBUQUERQUE, 2019).

Os profissionais de saúde, também possuem papel importante na abordagem da gravidez e IST's na adolescência, uma vez que, possuem conhecimento e habilidade para realizar junto aos professores práticas educativas relacionadas a prevenção de IST's e gravidez indesejada, entre as demais fragilidades dos adolescentes. Alem disto, é imprescindivel desenvolver momentos de trocas e diálogo, dado que a falta de informações corretas sobre o assunto contribuem para o aumento das IST's e gravidez na adolescencia (COSTENARO et al., 2020).

Albuquerque (2019) apresenta em sua pesquisa que após a utilização de materiais informativos e didáticos obteve-se resultados positivos. Aumentou significativamente o conhecimento dos alunos sobre os metodos contraceptivos, IST's, fecundação e as possibilidades de transmissão e contaminação por alguma IST por meio do contato sexual ou oral. 


\section{QUFN}

\section{CONCLUSÃO}

A tecnologia didática, na modalidade de cartilha informative, é uma ferramenta que contribui na promoção da saúde dos adolescents, sendo extensive aos seus familiars e amigos, pois aborda medidas de prevenção a gravidez e IST's na adolescência, bem como, características de cada IST e como agir frente a contaminação.

Espera-se que esse material seja positivo e leve maior conhecimento para os docentes e escolares. Que estes empoderem-se dos temas abordados e busquem promover o autocuidado e utilizar os métodos de prevenção corretamente, reduzindo o risco de gravidez e/ou contaminação por alguma IST na adolescência.

Por fim, a experiência de desenvolver uma cartilha informativa foi enriquecedora para a formação acadêmica de todos os participantes. Já que, conseguiu-se visualizar as diversas maneiras que podem ser desenvolvidas e articuladas as ações entre a saúde e a educação, visando a promoção e prevenção da saúde dos adolescentes. Ademais, essa interação é positiva para o processo de enfermagem, aproximando-se do ambiente escolar, clareando as possibilidades de promoção da saúde com os alunos e professors.

\section{AGRADECIMENTOS}

Agradeço a Universidade Franciscana pela oportunidade de participar de uma bolsa de Iniciação científica- PROBIC. Esta me instigou a ser uma acadêmica mais proativa e com tomada de decisão mais efetiva. Além de ter me oportunizado ingressar de maneira maios efetiva no mundo da pesquisa e das publicações científicas. Muito obrigada.

\section{REFERÊNCIAS}

AlBuquerque, A. F. L. L., PINHEIRO, A. K. B., LiNHARES, F. M. P., GUEDES, T. G. Tecnologia para o autocuidado da saúde sexual e reprodutiva de mulheres estomizadas. Revista Brasileira de Enfermagem, v.69, n.6, p.1099-106, 2016. DOI: http://dx.doi.org/10.1590/0034-7167-2016-0302 
ALBUQUERQUE, L. S. A. Produção de cartilha sobre infecções sexualmente transmissíveis e gravidez na adolescência de forma colaborativa com alunos do ensino médio. Dissertação (Mestrado). Mestrado Profissional em Ensino de Biologia em Rede Nacional - ProfBio, da Universidade Federal do Rio de Janeiro, Duque de Caxias, 2019.

costenaro, R. G. S., Jesus, M. I. A., OliveiRA P. P., ROOS, M. O., STANKOWSKI, S. S., TEIXEIRA, D. A. ABAID, J. L. W., SOUZA, M. H. T. Educação Sexual Com Adolescentes: promovendo saúde e socializando boas práticas sociais e familiares. Revista Brazilian Journal. of Development, Curitiba, v. 6, n.12, p. 100544-100560, 2020. DOI:10.34117/bjdv6n12-519.

FURLANETTO, M. F., LAUERMANNII, F., COSTA, C.B., MARIN, A. H. Educação sexual em escolas brasileiras: revisão sistemática da literatura. Caderno de. Pesquisa, v.48, n.168, p.550-571, 2018. DOI: https://doi.org/10.1590/198053145084.

HOLANDA, G. S. Validação de cartilha educativa sobre sífilis na gestação. Trabalho fina de curso (Monografia), Universidade Federal de Campina Grande, Cajazeiras, 2018.

STANKOWSKI, S. S., OLIVEIRA, P. P., FLORES, G. A., SOUZA, M. H. T., ABAID, J. L. W., COStenARO, R. G. S. Prevenção da gravidez e promoção da saúde de adolescentes: Revisão integrativa. Revista Brazilian Journal of Development (BJD), Curitiba, v.7, n.5, p. 44542-44556, 2021. DOI:10.34117/bjdv7n5-058

RODRIGUES, C. S. Implantação do Curso de Capacitação em Sexualidade para Professores do Ensino Fundamental II - com ênfase em IST/AIDS, Hepatites Virais e prevenção da gestação em crianças e adolescentes. Dissertação (Mestrado) em Infecção HIV/AIDS e Hepatites Virais na Área de Doenças Infecciosas e Parasitárias. Universidade Federal do Estado do Rio de Janeiro. Rio de Janeiro, 2017. 
RIZZON, B. B., SOUZA, V. B., MADEIRA, K., MACHADO, L. V., MAGALHÃES, M. Comportamento de risco para infecções sexualmente transmissíveis em estudantes do ensino médio. Revista Femina, v.49, n.1, p.52-7, 2021.

ROSANELI, C. F.; COSTA, N. B.; SUTILE, V. M. Proteção à vida e à saúde da gravidez na adolescência sob o olhar da Bioética. Physis: Revista de Saúde Coletiva [online], v. 30, n. 01, 2020.

VIEIRA, K. J., BARBOSA, N. G., MONTEIRO, J. C. S., DIONÍZIO, L. A., GOMESSPONHOLZ, F. A. Conhecimentos de adolescentes sobre métodos contraceptivos e infecções sexualmente transmissíveis. Revista Baiana de Enfermagem, v.35, e39015, 2021. 